\title{
ALFABETOS EN SERIES. CREACIÓN ARTÍSTICA A PARTIR DE DERIVAS GRÁFICAS URDIDAS CON LETRAS ${ }^{1}$
}

\begin{abstract}
Ricard HUERTA
Universitat de València

ricard.huerta@uv.es

$\int\left[\begin{array}{l}n \\ \text { Lún }\end{array}\right.$ ntroducción

Las letras han captado desde siempre mi atención, y han sido motivo de intereses variados en múltiples facetas. La lectura de libros y revistas forma parte de mi trayectoria vital, como un estímulo constante que progresa y que se incentiva en una especie de bucle que se retroalimenta sin cesar. Son muchos los recuerdos de aquellos momentos en que he leído libros que me han fascinado. Cuando tenía dieciséis años y estudiaba el bachillerato (entonces el llamado BUP) leí por mi cuenta (no era lectura obligatoria de clase) la novela de caballerías Tirant lo Blanc, de Joanot Martorell, en la edición íntegra publicada por Ariel y comentada por Martí de Riquer. Era de tal calibre mi emoción al leer aquel relato medieval que recuerdo incluso haber llorado en determinados pasajes. Aquí debo incidir en varios aspectos que conviene tener en cuenta para contextualizar esta cuestión:
\end{abstract}

1. Yo nací en 1963, es decir, en plena dictadura franquista. En aquella época estaba prohibido utilizar el catalán (mi lengua materna) en el ámbito público. Nunca estudié el catalán ni en la escuela, ni tampoco en la secundaria, ya que estaba completamente ausente en el espacio curricular oficial. Sin embargo, lo estudié por mi cuenta, ajeno a las disciplinas del orden establecido. Fueron algunos maestros y profesores quienes me animaron a iniciar las lecturas en catalán. Puede que por ello mi entusiasmo al leer el Tirant lo Blanc fuera, si cabe, doblemente estimulante, ya que la lengua se había convertido en un territorio apto para enfrentarse a la dictadura, y a las injusticias del régimen.

2. El catalán no solamente estaba prohibido en el entorno oficial (escuela, instituciones) y en el espacio público (medios de comunicación), sino que también padecíamos una injusta persecución en determinados ambientes. El catalán había permanecido muy

\footnotetext{
${ }^{1}$ Este trabajo forma parte del Proyecto I+D+i «Educación Patrimonial en España: Consolidación, evaluación de programas e internacionalización del Observatorio de Educación Patrimonial en España (OEPE)» con referencia EDU2012-37212.
} 
vivo en el entorno rural, y a quienes hablábamos en catalán se nos agredía con (supuestos) insultos del tipo «este es de pueblo». Pues bien, esta problemática de orden social y cultural pervive incluso en nuestros días, y es fuente de un exasperante (y falso) conflicto lingüístico que no aporta absolutamente nada positivo. Y menos aún a quienes usamos con normalidad nuestra lengua materna. Es más, desde posicionamientos ultraconservadores sigue constituyendo una fuente inagotable de ganancias políticas (y económicas). ¿Quién no ha escuchado alguna vez la absurda pregunta: «catalán y valenciano son lo mismo»?

3. Mis posicionamientos reivindicativos siempre tuvieron en cuenta las cuestiones sociales. Este talante innovador, acompañado de una ideología marcadamente de izquierdas (tengo conciencia de clase, soy un trabajador), influyen de manera perseverante en mi concepto de arte o de creación artística. No creo que estén tan lejos mis esfuerzos por dignificar mi lengua materna o mi propensión a utilizar el arte como herramienta de cambio social. En ambos casos se trata de visibilizar las injusticias y de proponer mejoras que puedan resultar beneficiosas para la mayoría de personas. Por tanto, los esfuerzos y la lucha impregnan desde siempre mi trayectoria personal y profesional.

Aquellas lecturas de adolescencia y juventud se convirtieron, con el tiempo, en semillas que posteriormente dieron como fruto series de grabados inspiradas en temas literarios (Alfabet del Tirant, Llibre d'Amic e Amat, Alfabet d'Alexandre). Esta fértil relación entre literatura y artes visuales es una componente fundamental de mi trabajo artístico. Pero debo decir que existe otra evidencia a tener en cuenta en este proceso de acercamiento entre textos e imágenes: el escenario de la comunicación. Cuando analizo mi trayectoria e intento ordenar, o al menos tejer, mis múltiples intereses (arte, educación, alfabetos, literatura, tipografía, museos, cine, ciudad, medios), compruebo que es el dispositivo de la comunicación el que reúne y amalgama todas estas cuestiones, aparentemente independientes entre ellas. De hecho, una de las carreras universitarias que cursé fue la de Comunicación Audiovisual, precisamente porque necesitaba reforzar mis conocimientos teóricos sobre los medios de comunicación. Así pues, la pasión por «comunicar» es la matriz en la que caben todas las disciplinas y materiales que manejo. Intento ser un buen «comunicador», tanto en la vertiente de la creación artística como en mi muy estimada faceta de profesor, de docente, de trabajador de la enseñanza.

\section{Metodología}

El presente relato se ha elaborado a partir de la metodología de los estudios de caso (Stake, 2005; Yin, 2003). Al haber elegido mi propia trayectoria como artista y educador, este trabajo de revisión y análisis se integra dentro de las llamadas narrativas personales, concretamente en el espectro de las 
denominadas Historias de Vida (Hernández et al., 2011). Las historias de vida constituyen un campo de estudio que plantea desafíos, que no puede aplicarse como una fórmula estricta y que se vincula al giro evidenciado en la investigación en Humanidades y Ciencias Sociales de las últimas décadas. En este sentido cabe preguntarse, en un ejercicio de reflexividad, por los aspectos sociales, culturales y académicos que han promovido este giro biográfico que tanto afecta a la investigación sobre el profesorado. Yo me considero un docente, un educador en artes, y mi planteamiento creativo afecta tanto a mis resultados artísticos como a mi labor educativa. Es más, no podría entender la una sin la otra. Cuando trabajo en el estudio refuerzo mis posibilidades docentes. Cuando elaboro acciones educativas en el aula estoy apelando constantemente a mis planteamientos resolutivos como artista. Es así, se trata de ámbitos que se complementan y se refuerzan. Ahora mismo, al reflexionar sobre mi producción como artista, estoy funcionando como un investigador, pero sin perder nunca de vista mi trayectoria como docente. En las metodologías que conocemos como arts based research se encuadra este posicionamiento. Se trata de algo que Rita Irwin ha denominado artography, un término que incluye las tres facetas de artista, educador e investigador $(a / r / t=$ artist, researcher, teacher $)$. Este concepto artográfico (Irwin, 2013) acompaña de manera íntima al hecho de implicarme en reflexionar sobre mi propio trabajo mediante un relato en el que expongo una narrativa personal de corte autobiográfico. Así pues, las Historias de Vida adquieren aquí una concepción biográfica que sirve al autor para reflexionar sobre su propia experiencia. Esta experiencia recoge tres décadas de conexión entre la producción artística y la función docente.

Presento, por tanto, un ejercicio de reflexividad, lo cual comporta asumir las problemáticas que surgen cuando se toma como guía esta perspectiva de investigación. Investigo desde un posicionamiento privilegiado, pero al mismo tiempo escurridizo, ya que se plantea el riesgo evidente de interpretar el propio trabajo desde una perspectiva complaciente. Intentaré evitar esta actitud resbalosa, orientando la mirada en un sentido más crítico, huyendo de las habituales aunque poco combativas zonas de confort. Revisaré todos aquellos componentes que han ido dando forma a mi casi obsesión por las letras y el alfabeto a la hora de generar artefactos visuales. Es necesario asumir, desde la humildad del profesor atento, el gran valor que adquieren las constantes aportaciones del alumnado con quien se comparte la práctica docente. El deseo de transmitir nuevas ideas se refuerza al afrontar los retos que plantea el alumnado. Estos retos se reactivan al iniciarse cada curso, ya que mientras nosotros como profesores tenemos paulatinamente más años, el alumnado permanece con una edad similar en cada convocatoria anual. El reto que significa atender y observar las necesidades que genera dicho alumnado nos anima a «rejuvenecer» obstinadamente nuestros recursos y nuestras propuestas. Del mismo modo que ante un lienzo siempre se trabaja desde un posicionamiento situado y desde una historia particular, ante al alumnado también se ejerce una acción situada, algo que nos impulsa a revisar constantemente nuestras posibilidades creativas y educadoras. 


\section{Las letras como signos y el influjo semiótico}

Mi formación artística parte de los estudios de música en conservatorio, donde realicé mi carrera desde los ocho hasta los diecinueve años de edad. También ejercí como profesor de música en conservatorio durante cinco años (1985-1989). Esta preparación musical deja varias huellas en mi posterior evolución como artista visual y como docente:

a. El interés y la seducción por los «ritmos» y las «estructuras».

b. La necesidad de funcionar en equipo (la interpretación musical así lo requiere).

c. La experiencia de «actuar» en público, y por tanto la capacidad de interactuar con un auditorio.

d. El deseo de comunicar a través del arte, en este caso mediante la música.

e. Un acercamiento al lenguaje escrito de las partituras musicales.

f. La posibilidad de dialogar con otros artistas o creadores.

Todo este bagaje, que procede de mi formación como músico, ha sido siempre un aliciente para reactivar de manera constante mi particular escenario creativo. Cuando a los diecisiete años decidí estudiar Bellas Artes en la Facultad de San Carlos de la Universitat Politècnica de València (con pocos años de trayectoria como facultad), fue en realidad una opción que me acercaba al entorno universitario. Necesitaba entrar en contacto con el mundo académico, y la opción de la nueva carrera de Bellas Artes encajaba con mi tradicional entusiasmo por el dibujo y la pintura. En este sentido debo agradecer el ejemplo del profesorado de dibujo y diseño, quienes, mientras estudiaba secundaria, me animaron en esta dirección profesional. Si bien todos los y las docentes del Institut Josep de Ribera de Xàtiva (centro en el que cursé el BUP y el COU) fueron estimulantes y supieron transmitirme un verdadero interés por todas y cada una de las materias, lo cierto es que los de dibujo captaron mi mayor atención.

Al formarme en la Facultad de Bellas Artes, mis intereses se volcaron de nuevo en el mundo de la comunicación. No perdamos de vista que estoy hablando de la década de 1980, unos años esplendorosos si valoramos lo que significaron para el entorno de la semiótica y la lingüística, impregnadas por entonces de un espíritu estructuralista (y post-estructuralista). No dudé al optar por la especialidad de Grabado, lo cual me llevaba a transitar por el camino de la tradición de la imprenta (Briggs y Burke, 2002), pasando por la influencia social de los medios (Benjamin, 1983), y encaminándome hacia las veleidades de las mitologías mediáticas del lenguaje (Barthes, 1986). Uno de los motivos ancestrales por los que me interesaba el grabado tiene que ver con la relación entre las letras y las imágenes. Nadie duda del tremendo acoplamiento que vertebra el mundo de la edición. Libros y revistas utilizan como material de base tanto los textos como las imágenes, generando una fusión entre ambos lenguajes. Mi aproximación a las revistas también está emparentado con mi infancia. Durante años, mi madre coleccionó la revista Garbo, una publicación semanal de información general (ahora podría entrar dentro del esquema de prensa rosa). Ella conservaba estos ejemplares 
coleccionados en una caja que guardaba en uno de los armarios de mi habitación. Yo devoré aquellas revistas, en las que, entre otras exquisiteces, podía leer las viñetas de cómic de personajes como Daniel el travieso o Kalikatres, así como unos dibujos que estaban en la más pura línea «chic» de lo que actualmente nos ofrece el ilustrador Jordi Labanda. Pero lo que más me llamaba la atención de aquellas páginas impresas era la jugosa relación entre los textos, las imágenes, y los diseños para cabeceras de artículos o para secciones de la revista. Aquí está la fuente primigenia de lo que años después sería mi trabajo de tesis doctoral, algo que posteriormente me acercaría a los estudios culturales y a la cultura visual (Walker y Chaplin, 2002; Mirzoeff, 2003).

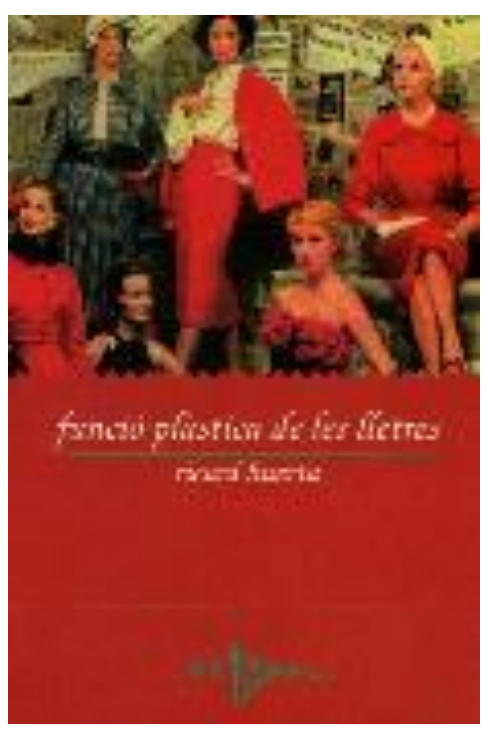

Fig 1. Portada del libro Funció plàstica de les lletres, editado por

Bullent. Imagen cortesía del artista.

La influencia de Roland Barthes en mi investigación para la tesis fue clave. Pero también estuvieron presentes de manera decisiva los estudios publicados por el Groupe $\mu$, así como los contactos con diseñadores, tipógrafos, impresores y periodistas. Lo cierto es que cuando en 1992 defendí la tesis doctoral titulada Funció plàstica de les lletres en les publicacions periòdiques espanyoles dels anys '50, ya llevaba más de una década exponiendo de manera habitual en galerías de arte, al tiempo que presentaba mis obras en muestras colectivas e individuales. Una revisión de lo presentado obtuvo el Primer Premi d'Investigació sobre Comunicació de Masses de la Generalitat de Catalunya, y un resumen simplificado del trabajo fue publicado posteriormente por Edicions del Bullent (Huerta, 1994). Durante estos años, además, ejercí como diseñador gráfico tanto a nivel individual como en colaboración con Yolanda Ferrer, con quien compartía esfuerzos en el colectivo La Mona Gráfica.

\section{Artistas visuales que han influido en mi relación creativa con las letras}

La formación como grabador en la carrera de Bellas Artes está vinculada al conocimiento y a la pasión que han ejercido en mí desde siempre ciertos artistas que usan letras en sus obras. Puede que el caso más emblemático sea Jasper Johns, de quien valoro no solamente su propensión a las letras y los números, sino el atractivo que provoca en mí su gestual y provocador tratamiento de los símbolos en general. También Cy Twombly con sus caligrafías impregnadas de misticismo mediterráneo, así como Robert Rauschenberg con sus texturas rociadas de tintes mediáticos, constituyen una tríada excepcional. Hace poco pude saber que Jasper Johns y Robert Rauschenberg habían sido pareja estable durante seis años, y que nunca lo ocultaron. Fue su entorno quien nos impidió conocer este importante detalle de sus biografías. También Cy Twombly era homosexual, y jamás escondió su orientación. Lo cierto es que en la actualidad, y teniendo en cuenta mi activismo en defensa de los derechos de las personas y los colectivos LGTB, he encontrado en aquellas fuentes los más increíbles ejemplos de 
coherencia en la obra que nos han legado. Otros artistas norteamericanos a quienes debo reconocer mi gratitud son Edward Ruscha (Lyvet, 1982) y Robert Indiana.

La influencia de Antoni Tàpies en mi obra tiene que ver con el uso de las texturas y con el placer que experimento al elaborar un discurso muy impregnado de un cierto misticismo orientalista. Nada que ver con la religión (no soy creyente). Lo que revelan mis grabados es un planteamiento más bien simbólico, algo que Tàpies relacionaba con el carácter comunicativo del muro. Los materiales y los simbolismos que generan, además de las injerencias del grafiti, adquieren significación en tanto que nosotros somos capaces de captar dicho sentido en cada huella de la superficie marcada. El carácter iconográfico que supuran elementos tan sencillos como las cruces, las letras, los números o las figuras geométricas consigue evocar alegorías relacionadas con nuestro propio mundo interior. Las letras, según indicaba Tàpies, también están en nuestro cuerpo (la M en la mano, la $\mathrm{S}$ en las arrugas del pie). Esta capacidad de transmitir que adquiere el simbolismo de las texturas es algo que siempre he intentado evidenciar en mis grabados.

También el trabajo de diseñadores gráficos como Javier Mariscal o Pepe Gimeno, ambos con trayectorias muy marcadas por su capacidad para la creación tipográfica y caligráfica, han influido en mi itinerario creativo, tanto al ejercer de diseñador, como al producir pinturas y grabados destinados a exponerse en galerías de arte y en

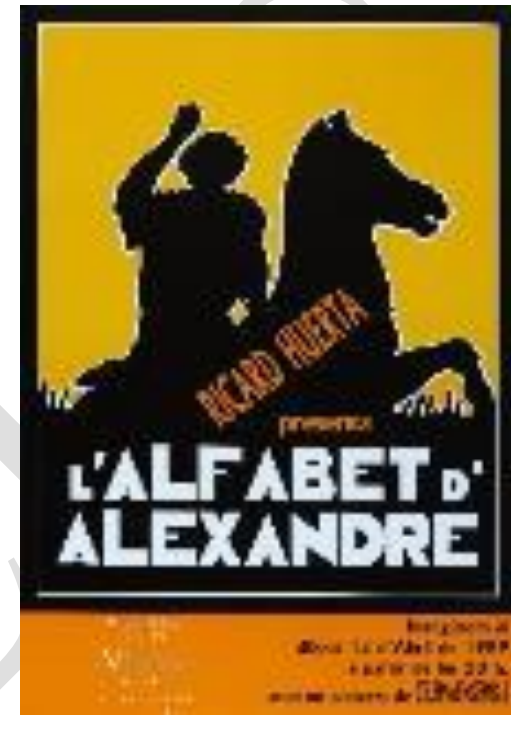

Fig. 2. Cartel de la exposición l'Alfabet d'Alexandre en Galería Viciana, 1989. Imagen cortesía del artista. museos. Vuelvo a incidir en el influjo constante de la literatura, ya que si para el Alfabet del Tirant

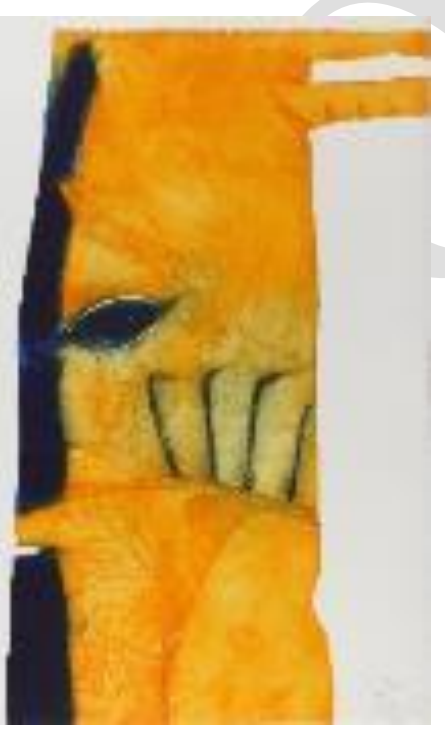

Fig. 3. "F" de Filippo de Macedonia, padre de Alejandro Magno, grabado de la serie l'Alfabet d'Alexandre. Impresión en técnica mixta sobre papel. Imagen cortesía del artista. resultó providencial la lectura de la novela de Joanot Martorell, para el Alfabet d'Alexandre fue clave la trilogía sobre Alejandro Magno escrita por Mary Renault, y de manera muy especial su libro $\mathrm{El}$ muchacho persa (Renault, 1984). El libro lo leí en la isla de La Palma, donde viví durante seis meses. La carpeta de los veintiún grabados del Alfabet d'Alexandre se gestó en parte en Italia, al haber obtenido por concurso la beca de Ampliación de Estudios Universitarios de la Diputación de Valencia en su modalidad de Artes (la anteriormente denominada Pensión en Roma para Artistas).

La trilogía, las tres series de grabados dedicadas a grandes personajes de la historia, la componen l'Alfabet d'Alexandre, l'Alfabet del Tirant y l'Alfabet de Jesucrist. Se gestaron y se produjeron entre 1988 y 1993. Todas las partes del proceso fueron ejecutadas personalmente, desde la creación de las ideas, pasando por la selección de contenidos, y sobre todo atendiendo a la totalidad del momento de intervención en las planchas de los grabados, así 
como en el entintado y la estampación de cada una de las nueve copias de las que consta cada serie. Disponía de un taller con tórculo, en el que se estamparon todos estos grabados. Para mí siempre fue muy vivencial poder tener la capacidad de llevar a cabo cada uno de los momentos que requiere este meticuloso proceso. Si pude hacerlo fue porque dediqué muchísimo tiempo a esta empresa, un tiempo en el que me sumergía completamente en cada fase de la realización de los grabados. Era algo casi visceral. Siempre entendí la creación como un desarrollo de posibilidades, como una presión interna que necesitaba emerger. La meta consistía en logar superar aquel reto. Pienso que ahora sería incapaz

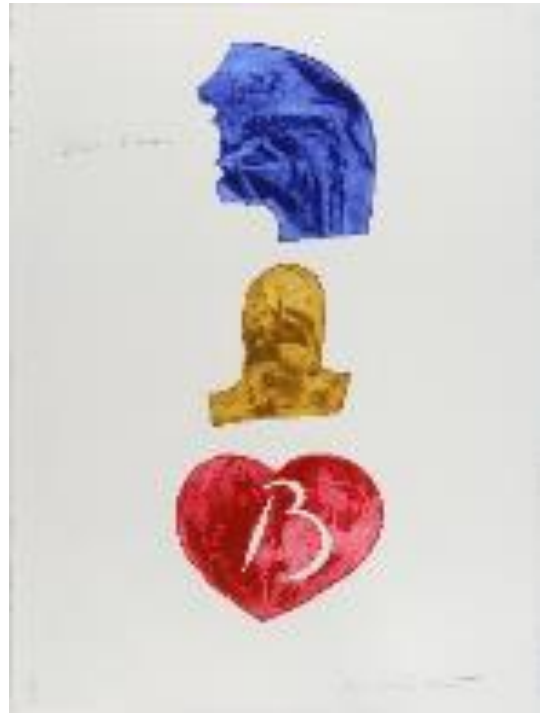

Figura 4. "B" de Blanca de la serie de grabados del Alfabet del Tirant. Impresión en técnica mixta sobre papel. Imagen cortesía del artista. de volver a conseguir algo similar. Volcaba todas mis energías en el desarrollo creativo de aquellas carpetas de grabados.

Los ejemplos de las figuras 4 y 5 que ilustran este texto corresponden a la letra «B» de Blanca de la serie de grabados del Alfabet del Tirant, y a la letra «E» de Evangelios de la serie de grabados del Alfabet de Jesucrist. En ambos casos la correspondencia con elementos lingüísticos y literarios resulta más que evidente. Blanca es el nombre de la madre del caballero Tirant (de ahí su mote «lo blanc», por ser hijo de Blanca). Aquí se realiza una combinación de la idea de «madre» con el concepto de «lengua materna». Para mí el Tirant era una extraordinaria representación literaria escrita en mi lengua materna, por eso utilizo símbolos que la representan de manera metafórica: una lengua, un corte transversal representando los órganos fónicos, y un corazón que alude al amor hacia la madre y hacia la lengua materna. En el caso de los Evangelios, los libros sagrados están representados por los cuatro símbolos de los evangelistas: el león de San Marcos (aquí el león de la Metro Goldwin Mayer), el águila de San Juan (aquí como Cervezas el Águila), el toro de San Lucas (aquí el toro de Osborne) y el hombre como representación de San Lucas (aquí un insultante Radiant Child de Keith Haring).

En las series de grabados de esta trilogía se pueden verificar las constantes correspondencias descriptivas que me llevaron a crear estas simbologías y metáforas. La influencia de la literatura y de los márgenes del lenguaje, en sus diferentes manifestaciones, constituyen el origen primigenio de las afinidades $y$ correspondencias generadas. Excepto el Alfabet d'Alexandre (que contó con una colección de carteles), las otras dos series tuvieron su catálogo correspondiente. En los catálogos del Alfabet del Tirant y el del Alfabet de Jesucrist no se reproducían fotográficamente los grabados de la carpeta, sino que se realizaron ilustraciones

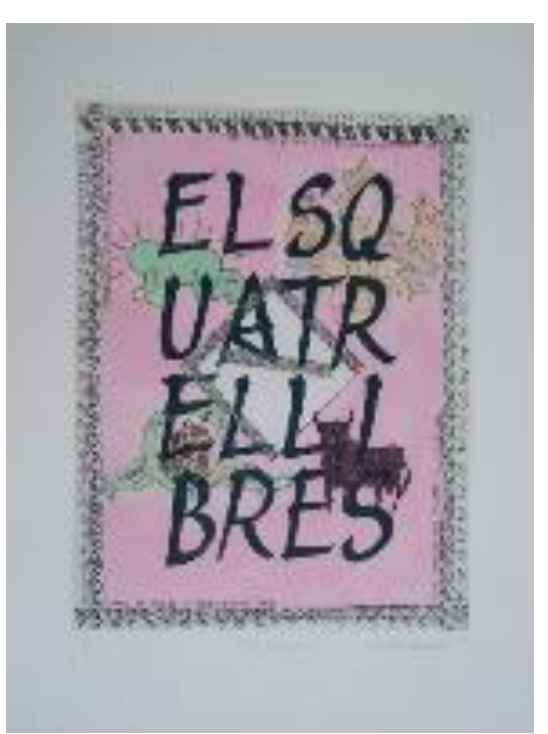

Fig. 5. "E" de Evangelios de la serie de grabados del Alfabet de Jesucrist. Impresión en técnica mixta sobre papel. Imagen cortesía del artista. 
específicas para la edición. En ambos casos participaron escritores y profesorado de Filología quienes aportaban sus creaciones literarias al volumen. Entre otros participaron Josep Piera, Albert Hauf, Jesús Huguet, Toni Cucarella, Carme Miquel o Julio Calvo. Siempre planteé los catálogos como una posibilidad más de creación, concibiéndolos como libros de artista, y evitando así que se convirtiesen en mera comparsa de la exposición. La presencia de la literatura invade, por tanto, buena parte de mis trabajos de las décadas de 1980 y 1990.

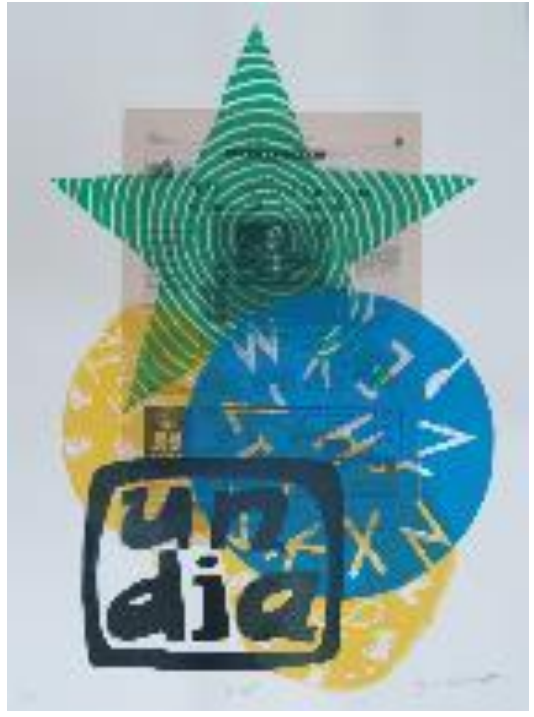

Fig. 6. Grabado de la serie Un día correspondiente a la expresión en catalán de la carpeta 7/9. Impresión en técnica mixta sobre papel.

Imagen cortesía del artista.

En 1996 presenté la exposición titulada Un día. La muestra se inauguró al mismo tiempo en tres galerías: Estiarte, en Madrid, Diagonal Art, en Barcelona, y Viciana, en Valencia. Los veintiún grabados de cada una de las nueve carpetas seriadas son siempre diferentes, ya que cada imagen está concebida a partir de una página de periódico. Los periódicos fueron recogidos en una performance recorriendo durante un día veintiún kioscos de Barcelona, al mismo tiempo que hablábamos con siete personas (con quienes habíamos acordado la hora y el lugar del encuentro), y realizando una acción delante de tres instituciones: la Fundació Miró, la Fundació Tàpies y la Fundació La Caixa (por entonces situada en Gran de Gràcia). El fotógrafo Francesc Vera recogió en imágenes la jornada, mientras Hortensia Vinyoles registraba en vídeo todas las acciones realizadas. El catálogo de la exposición se transformó en realidad en un libro de poemas (Huerta, 1996). De nuevo huía del catálogo de reproducciones, y elaboraba un libro de artista, en este caso con poemas propios, composiciones en las que relataba los motivos de la acción.

Además de elaborar el discurso gráfico en los grabados y de incidir en las relaciones con la literatura, estas colecciones se presentaban en carpetas diseñadas específicamente, bien en tela, en madera o en acero inoxidable. Los montajes en las exposiciciones siempre fueron acompañados de acciones, y los catálogos se presentaban como una pieza más del conjunto. Creo que estas preocupaciones por mantener un elevado nivel de exigencia emparentan dichas creaciones con la definición que nos ofrece Sennett (2013).

\section{Las series Mujeres Maestras y el concepto artográfico de creación, investigación y docencia}

Ya en la última década, una parte destacada de mis realizaciones artísticas han tenido como referencia el proyecto titulado genéricamente Mujeres Maestras (Huerta, 2012). Se inició en 2006 con la serie Dones Mestres, para rendir homenaje al colectivo de las docentes. Soy profesor universitario, formador de maestros en las titulaciones de Magisterio, y una mayoría de mi alumnado son mujeres. Por este motivo quise acercarme a sus geografías identitarias a través del arte. En estas series se 
conjugan tres miradas hacia las maestras: la mirada del artista que las retrata, la mirada del alumnado que las dibuja, y la propia mirada autobiográfica de las docentes, quienes mediante un vídeo explican sus deseos, anhelos y problemáticas. Las series de pinturas, de diferentes dimensiones, han estado expuestas en galerías y museos de varias ciudades y universidades españolas, uruguayas y chilenas. También se expuso la serie Maestras de Europa en la Sala Espace Atrium del Parlamento Europeo de Bruselas.

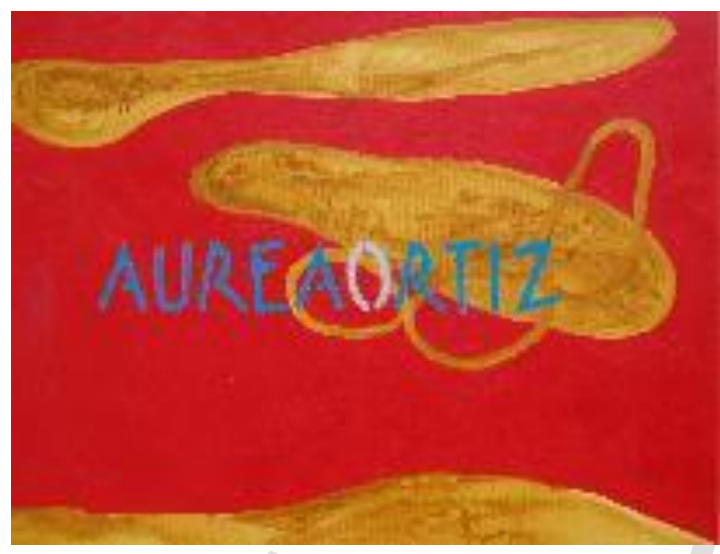

Fig. 7. Pintura de la serie Mujeres Maestras dedicada a la profesora Áurea Ortiz. Imagen cortesía del artista.

\section{Fotografiando las letras de las ciudades}

Entre los intereses que más me han motivado desde hace años se encuentra la pasión por las letras urbanas. Una parte de mi obra la constituyen las fotografías que realizo de las letras de las ciudades (Huerta, 2008). Si bien nunca ha sido expuesta en galería hasta el momento, lo cierto es que en parte viene publicándose en libros o revistas, y sobre todo la he utilizado como recurso de imágenes para conferencias, clases y seminarios. La apropiación de la ciudad como deriva y experiencia artística (Careri 2002 y 2014) encarna la posibilidad de generar una mirada alternativa hacia lo urbano (Huerta, 2010), entendiendo la ciudad como una representación visual (Huerta, 2011; Lynch, 1998; Romano,

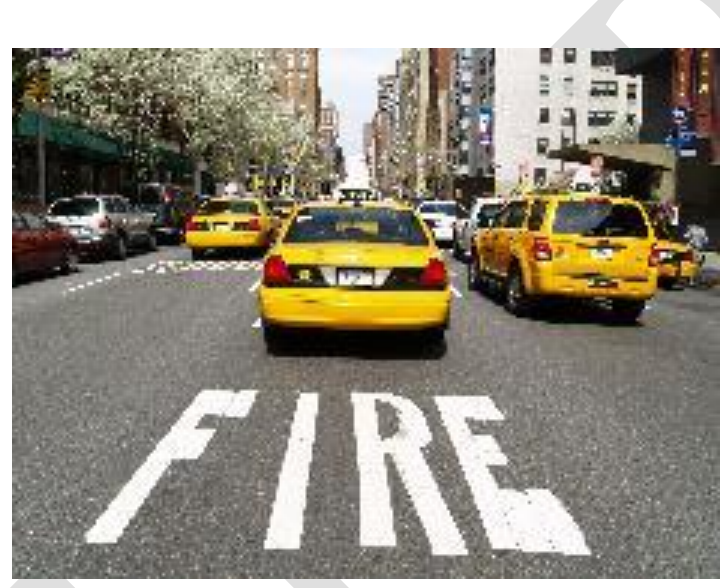

Fig. 8. Letras pintadas en el asfalto de una calle en Nueva York. Imagen cortesía del artista. 2008). De este modo la experiencia a través de lo urbano nos capacita para musealizar el entorno (Huerta, 2005; Satué, 1984), construyendo nuevas derivas (Huerta, 1997) que acaban incluyendo las reflexiones de tipo sociológico (Codeluppi, 2014), urbanístico (Lynch, 1998), filosófico (Benjamin, 2005), literario (Millás, 2006), e incluso pedagógico (Duncum, 2008; Huerta, 2013) o estético (Csikzentmihalyi, 1990; Errázuriz, 2006). Todas estas posibilidades que nos brindan las diferentes apreciaciones de la ciudad, en este caso se concentran a partir de las lecturas que ofrecen las letras urbanas (Huerta, 2006).

Soy consciente que al investigar sobre un tema como el de la educación en museos tiendo a plantear aspectos relacionados con el patrimonio (Huerta y Calle, 2013) desde una perspectiva pedagógica, animando al profesorado a reflexionar sobre sus potencialidades (Giroux, 1990) y concibiendo el arte como una construcción colectiva (Laddaga, 2006). Pienso que es necesario transmitir al futuro profesorado el valor histórico y simbólico del alfabeto (Huerta, 2004), para lo cual se puede hacer uso de la gran tradición histórica de los estudios sobre caligrafía y tipografía (Frutiger, 


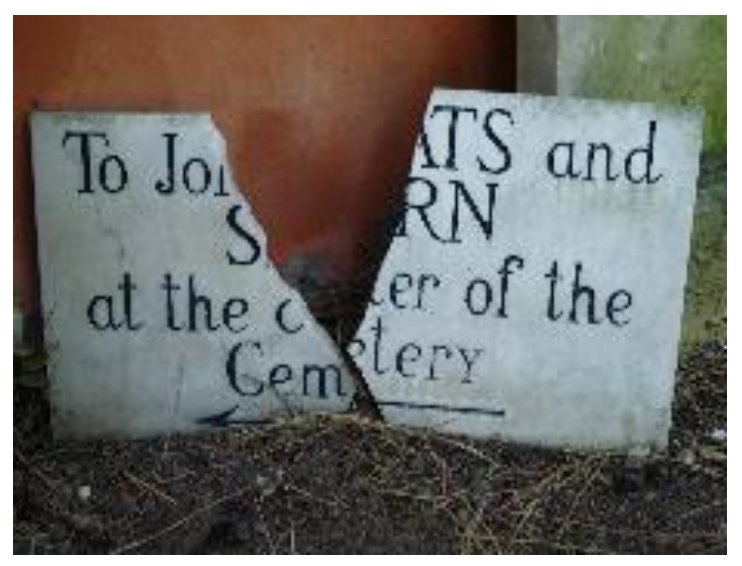

Fig. 9. Inscripción sobre mármol. Cimitero Inglese. Roma. Imagen cortesía del artista.
2007; Humez, 1987), sin perder de vista su relación con el arte (Satué, 2007), ni tampoco dejar de lado las constantes reverberaciones literarias que tan bien complementan este tipo de cuestiones que transitan en sutiles márgenes fronterizos (Maffesoli, 2010; Mirzoeff, 2006; Morris, 2007; Saramago, 2007).

\section{Conclusiones}

Las letras como artefacto visual pueden originar soluciones gráficas aptas para la creación artística, tal y como se observa en la obra de numerosos artistas a lo largo de la historia. Esta capacidad comunicativa de las letras las convierte en formas legibles que, gracias a su propia carga polisémica, producen una deriva de simbologías y significaciones cercanas a las interpretaciones que ofrecen las obras de arte. Desde la cultura visual entendemos que la apreciación crítica de nuestro entorno favorece una mirada más responsable y fructífera. En el caso concreto de mi obra, observo que siempre he utilizado las letras del alfabeto como argumento válido para la expresión, pero también como espoleta con la que incitar al alumnado a reconsiderar su contexto cultural. Reivindico el alfabeto como potente estrategia visual, y desde mi posición de docente y artista, entiendo que este tipo de premisas han de servirnos para mejorar la formación de la ciudadanía. En las series que he realizado, independientemente de si se ha optado por el grabado, la fotografía, la pintura o la performance, lo cierto es que el papel de las letras deviene siempre primordial. Para finalizar, debo confesar que es la primera vez que analizo mi propia obra, es decir, que la reflexión sobre mi labor artística nunca la había planteado en forma de artículo publicable.

\section{Bibliografía}

BARTHES, R. (1986): Lo obvio y lo obtuso. Imágenes, gestos, voces. Barcelona, Paidós.

BENJAMIN, W. (1983): L'obra d'art a l'època de la seva reproductibilitat tècnica. Barcelona, Ed. 62. (2005): Libro de los pasajes. Madrid, Akal.

Briggs, A., y P. BuRKe, (2002): De Gutenberg a Internet. Una historia social de los medios de comunicación. Madrid, Taurus.

CARERI, F. (2002): Walkscapes. El andar como práctica estética. Barcelona, Gustavo Gili. (2014): «Walkscapes diez años después», URBS Revista de Estudios Urbanos y Ciencias Sociales, 4/1, pp. 207-213.

CodeluPPI, V. (2014): Metropoli e luoghi del consumo. Milano, Mimesi. 
Csikzentminalyi, M. (1990): The Art of Seeing. An Interpretation of the Aesthetic Encounter. Los Angeles, The J. Paul Getty Trust.

Duncum, P. (2008): «Holding Aesthetics and Ideology in Tension», Studies in Art Education, 49/2, pp. 122-135.

ERrÁzUriz, L. H. (2006): Sensibilidad estética. Un desafío pendiente en la educación chilena. Santiago de Chile, PUC.

FRUTIGER, A. (2007): Reflexiones sobre signos y caracteres. Barcelona, Gustavo Gili.

GIROUX, H. (1990): Los profesores como intelectuales. Hacia una pedagogía crítica del aprendizaje. Barcelona, Paidós.

HERNÁNDEZ, F., J. SANCHO y J. RIVAS, coords. (2011) Historias de vida en educación: Biografías en contexto. Barcelona, Universitat de Barcelona.

Huerta, R. (1994): Funció plàstica de les lletres. Picanya, Bullent. (1996): Un dia. Bromera, Alzira. (1997): «Grafitis infantils: de cara a la paret», en F. M. GIMENO BLAY y M. ${ }^{a}$ L. MANDINGORRA LlavatA, eds., Los muros tienen la palabra. Materiales para una historia de los graffiti. Valencia, PUV, pp. 189-202.

- (2004): «Sangre o tinta. La tipografía como argumento liminar para una educación artística», en AA. VV., Ponencias Primer Congreso de Tipografía. Valencia, ADCV, pp. 178-186.

(2005): «Lletres que fan del carrer un museu», en AA. VV., Actas del I Congrés d'Educació de les Arts Visuals. Terrassa, Colbacat - Universitat de Barcelona.

- (2006): «La ciudad escrita, museo cotidiano», Aula de Innovación Educativa, 151, pp. 35-38.

_ (2008): Museo Tipográfico Urbano. Paseando entre las letras de la ciudad. Valencia, PUV. (2010): «I Like Cities; Do You Like Letters? Introducing Urban Typography in Art Education», International Journal of Art \& Design Education, 29/1, pp. 72-81.

- (2011): Ciudadana letra. Valencia, Institució Alfons el Magnànim (2012): Mujeres maestras. Identidades docentes en Iberoamérica. Barcelona, Graó.

(2013): «Docentes paseando por las letras de la ciudad», Arteterapia: Papeles de Arteterapia y Educación Artística para la Inclusión Social, 8, pp. 123-136.

HuERTA, R., y R. DE LA CALLE, eds. (2013): Patrimonios migrantes. Valencia, PUV.

IRWIN, R. (2013): «Becoming A/r/tography», Studies in Art Education: A Journal of Issues and Research, 54/3, pp. 198-215.

Humez, A. (1987): ABC et Cetera. The Life and Times of the Roman Alphabet. Boston, David R. Godine.

LAdDAGA, R. (2006): Estética de la emergencia. Buenos Aires, Adriana Hidalgo.

LIVET, A. (1982): The Works of Edward Ruscha. New York, Hudson Hills.

LYNCH, K. (1998a): La imagen de la ciudad. Barcelona, Gustavo Gili.

MAFFESOLI, M. (2010): La passion de l'ordinaire: miettes sociologiques. París, CNRS.

MiRzoefF, N. (2003): Una introducción a la Cultura Visual. Barcelona, Octaedro. 
(2006): «On Visuality», Journal of Visual Culture, 5/1, pp. 53-79.

MiLlás, J. J. (2006): El orden alfabético. Madrid, Punto de Lectura.

MoRris, J. (2007): Un mundo escrito. Barcelona, RBA.

RenAUlt, M. (1984): El muchacho persa. México, Grijalbo.

RoMANO, M. (2008): La città come opera d'arte. Torino, Einaudi.

SARAMAgO, J. (2007): Manual de pintura y caligrafía. Madrid, Punto de Lectura.

SATUÉ, E. (1984): Un museu al carrer. Lletres, imatges i tècniques dels rètols comercials a Catalunya.

Barcelona, Diputació de Barcelona.

- (2007): Arte en la tipografía y tipografía en el arte. Madrid, Siruela.

SENNETT, R. (2013): El artesano. Barcelona, Anagrama.

STAKE, R. E. (2005): Investigación con estudio de casos. Madrid, Morata.

WALKER, J. A., y S. CHAPLIN (2002): Una introducción a la cultura visual. Barcelona, Octaedro.

YIN, R. K. (2003): Case Study Research. Thousand Oaks, Sage. 